\title{
A proteomic approach identified growth hormone-dependent nutrition markers in children with idiopathic short stature Gunnel Hellgren* ${ }^{* 1}$, Björn Andersson ${ }^{\dagger 1}$, Andreas FM Nierop ${ }^{2}$, Jovanna Dahlgren ${ }^{1}$, Ze'ev Hochberg ${ }^{1,3}$ and Kerstin Albertsson-Wikland ${ }^{1}$
}

\author{
Address: ${ }^{1}$ Göteborg Pediatric Growth Research Center, Department of Pediatrics, Institute of Clinical Sciences, Sahlgrenska Academy, University \\ of Gothenburg, The Queen Silvia Children's Hospital, SE-416 85 Göteborg, Sweden, ${ }^{2}$ Muvara bv, Leiderdorp, The Netherlands and ${ }^{3}$ Meyer \\ Children's Hospital, Rambam Medical Center, and Technion - Israel Institute of Technology, Haifa, Israel \\ Email: Gunnel Hellgren* - gunnel.hellgren@vgregion.se; Björn Andersson - bjorn.andersson@medic.gu.se; \\ Andreas FM Nierop - nierop@muvara.nl; Jovanna Dahlgren - jovanna.dahlgren@vgregion.se; \\ Ze'ev Hochberg - z_hochberg@rambam.health.gov.il; Kerstin Albertsson-Wikland - kerstin.albertsson-wikland@pediat.gu.se \\ * Corresponding author †Equal contributors
}

Published: II December 2008

Proteome Science 2008, 6:35 doi:10.1186/1477-5956-6-35

This article is available from: http://www.proteomesci.com/content/6/1/35

(c) 2008 Hellgren et al; licensee BioMed Central Ltd.

This is an Open Access article distributed under the terms of the Creative Commons Attribution License (http://creativecommons.org/licenses/by/2.0), which permits unrestricted use, distribution, and reproduction in any medium, provided the original work is properly cited.
Received: 22 September 2008

Accepted: II December 2008

\begin{abstract}
Background: The broad range in growth observed in short prepubertal children receiving the same growth hormone $(\mathrm{GH})$ dose is due to individual variation in $\mathrm{GH}$ responsiveness. This study used a pharmaco-proteomic approach in order to identify novel biomarkers that discriminate between short non-GH-deficient (GHD) children who show a good or poor growth response to $\mathrm{GH}$ treatment.
\end{abstract}

A group of 32 prepubertal children with idiopathic short stature (ISS) were included in the study. Children were classified on the basis of their first year growth velocity as either good (high responders, $\mathrm{n}=13$; range, $0.9-1.3$ standard deviation score (SDS) or poor (low responders, $\mathrm{n}=$ 19; range, $0.3-0.5 \mathrm{SDS}$ ) responders to $\mathrm{GH}$ treatment ( $33 \mu \mathrm{g} / \mathrm{kg}$ daily).

Serum protein expression profiles before, and after I year of GH treatment, were analyzed on a weak cationic exchange array (CMIO) using surface-enhanced laser desorption/ionisation time-offlight mass spectrometry (SELDI-TOF-MS).

Results: Changes in the intensity of two protein peaks (I3.788 kDa and 17.139 kD) during the study period allowed the correct classification of $82 \%$ of children as high and low responders, respectively. The $13.788 \mathrm{kD}$ peak, transthyretin, decreased in the high-responder group and increased in the low-responder group during I year of $\mathrm{GH}$ treatment, whereas the $17.139 \mathrm{kDa}$ peak, apolipoprotein A-II (Apo A-II) decreased in the high-responder group and remained unchanged in the low-responder group. These peaks were identified by the consistency of peak pattern in the spectra, serum depletion experiments using specific antibodies and mass spectrometry.

Conclusion: Our results suggest that transthyretin and apolipoprotein A-II may have a role in GH sensitivity and could be used as markers to predict which short prepubertal children with ISS will show a good or poor response to $\mathrm{GH}$ treatment. 


\section{Background}

Short stature is believed to be the result of many factors. These include genetics, environment and many different hormones. The growth hormone (GH)-dependent component of growth during childhood is believed to result from the integrated balance between GH secretion and $\mathrm{GH}$ responsiveness in each child. Short stature in GH-deficient (GHD) children arises as a result of poor GH secretion, whereas short stature in children with idiopathic short stature (ISS) may be due to differences in the degree of GH responsiveness.

As we know that GH and insulin-like growth factor I (IGFI) play a major role in the regulation of postnatal growth, most studies investigating GH responsiveness in patients have involved assessments of mutations in single genes involved in the GH/IGF-I axis [1,2]. However, very few growth-related mutations have been identified by this approach and it is clear that other, as yet unknown, factors must be involved in responsiveness to GH treatment.

Prediction models for growth response to GH treatment, a measure of GH responsiveness, suggest a role for auxological data, such as growth during infancy and childhood [3], familial differences in height, height standard deviation score (SDS) at treatment start and differences in midparental height, as well as the responsiveness of the GH/ IGF-I axis [4-7]. Variables used in these prediction models, however, explain only around $50-70 \%$ of the growth response to GH.

This study explored the utility of a pharmaco-proteomic approach for the identification of novel biomarkers that allow the prediction of GH treatment response. For this purpose we monitored changes in protein profiles using surface-enhanced laser desorption/ionization time-offlight mass spectrometry (SELDI-TOF-MS). We analyzed the expression of serum proteins before the start of GH treatment and after 1 year of treatment in prepubertal children with ISS and assessed differences in protein expression between patients with good and poor growth responses to GH treatment. By using this approach two nutrition proteins were identified that could be used to discriminate between good and poor GH treatment responders with respect to treatment response after 1 year of treatment, and to a lower degree before treatment.

\section{Subjects and methods Study population}

The procedure for study selection is shown in Figure 1. From a group of 546 short (height below -2 SD [8]) prepubertal children receiving GH treatment, the 40 children with highest and the 40 children with lowest response on the basis of their first year growth were selected. From this group of 80 children, 51 children with ISS and a maxi- mum peak of $\mathrm{GH}$ secretion $\left(\mathrm{GH}_{\max }\right)$ on the arginine-insulin tolerance test (AITT) $>5 \mu \mathrm{g} / \mathrm{L}$ were identified. Of this subgroup, 19 were classified as high treatment responders (first year height increase of 0.9-1.3 SDS), and 32 as low treatment responders (0.1-0.5 SDS). Only patients for whom two high quality mass spectra measurements were available at each time point were included in further statistical analysis. The final study population included 37 children (14 high responders; 23 low responders) for whom protein expression data were available before the start of GH treatment and 32 children (13 high responders; 19 low responders) for whom protein expression data were available after 1 year of GH treatment.

Auxological data for children for whom two high quality spectra were available both before treatment and after 1 year are presented in Table 1.

All patients were of Caucasian origin and children with dysmorphic syndromes or chronic diseases, were excluded from the study. Data analysis included the following variables; $\mathrm{GH}_{\max }$ after AITT, spontaneous GH secretion level over a $24 \mathrm{~h}$ period, IGF-I level, IGF-binding protein 3 (IGFBP-3) level and leptin level [6]. The references used for SDS calculations are [8] for height and weigh and [9] for IGF-I. The children received daily injections of $33 \mu \mathrm{g} / \mathrm{kg}$ recombinant human GH produced from the companies with GH products registered in Sweden.

\section{Study design}

Blood samples were taken at two different time-points. The first sample was taken before the start of GH treatment and the second 1 year after the start of GH treatment. All samples were stored at $-70^{\circ} \mathrm{C}$ for between 4 and 20 years and were not thawed until the time of analysis.

\section{Ethics}

The study was performed in agreement with the Helsinki Declaration and approved by the Ethical Committee at the Sahlgrenska Academy, University of Gothenburg (no 270-88 and 71516-05). Informed consent was obtained from the parents of each child and from the child if old enough.

\section{SELDI-TOF serum protein profiling}

Serum samples were thawed, denaturated and fractionated using serum anion exchange beads according to protocols provided by Bio-Rad Laboratories, Hercules, CA. Preliminary analyses were performed on all serum fractions from four low and four high responders, using weak anion-exchange (CM10), immobilized metal affinity capture (IMAC30) and reversed phase (H50) arrays (Bio-Rad Laboratories) in order to determine which conditions should be used for analysis of the whole study group. 


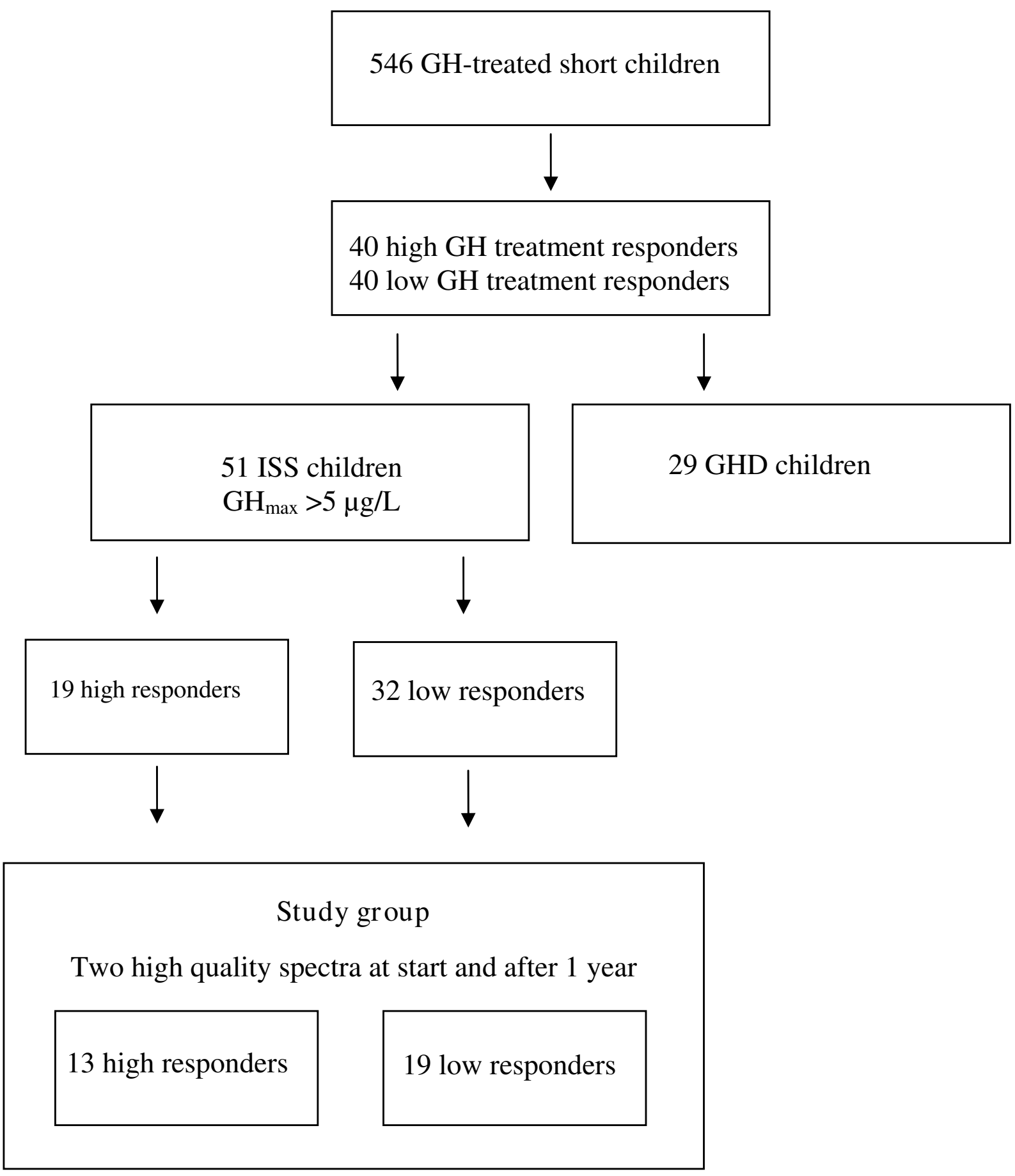

Figure I

The procedure for study group selection. 
Table I: Auxological data for the children included in the analysis, from whom high-quality spectra were available both before and after I year of GH treatment.

\begin{tabular}{|c|c|c|c|c|c|c|c|c|}
\hline \multirow[b]{2}{*}{ Variables } & \multicolumn{4}{|c|}{ High-responder group } & \multicolumn{4}{|c|}{ Low-responder group } \\
\hline & Median & Min & Max & $\mathrm{N}$ & Median & Min & Max & $N$ \\
\hline \multicolumn{9}{|l|}{ At birth } \\
\hline Gestational age (weeks) & 39 & 38 & 42 & 13 & 39 & 37 & 471 & 19 \\
\hline Height SDS & --1.49 & --3.94 & 1.34 & 13 & --1.93 & --3.82 & --0.18 & 19 \\
\hline Weight SDS & --1.90 & --2.77 & 1.59 & 13 & --1.20 & -2.89 & 0.80 & 19 \\
\hline \multicolumn{9}{|l|}{ Pretreatment } \\
\hline Delta height SDS during pretreatment yr & --2.84 & --3.57 & --2.24 & 11 & --2.88 & --4.13 & -2.17 & 18 \\
\hline \multicolumn{9}{|l|}{ At GH start } \\
\hline Gender $(\min =$ girls, $\max =$ boys $)$ & & 2 & 11 & 13 & & 4 & 15 & 19 \\
\hline AGA/SGA $(\min =A G A, \max =S G A)$ & & 8 & 5 & 13 & & 10 & 9 & 19 \\
\hline$* A g e(y r s)$ & 5.84 & 3.90 & 10.53 & 13 & 9.31 & 3.32 & 11.96 & 19 \\
\hline Height SDS & --2.66 & --3.84 & --2.04 & 13 & --2.84 & --4.33 & --1.59 & 19 \\
\hline Weight SDS & --2.51 & --3.56 & --1.72 & 13 & --2.20 & --4.11 & --1.15 & 19 \\
\hline Father height SDS & --0.98 & --1.59 & 2.12 & 13 & --0.98 & --2.95 & 0.85 & 19 \\
\hline Mother height SDS & --0.80 & --2.04 & 1.15 & 13 & --1.58 & --2.93 & 0.56 & 19 \\
\hline MPHSDS & --0.54 & --1.81 & 0.55 & 13 & --1.21 & -2.46 & 0.63 & 19 \\
\hline $\mathrm{GH}_{\max }$ AITT & 21.86 & 20.20 & 48.07 & 13 & 28.75 & 18.20 & 63.86 & 17 \\
\hline$* \mathrm{GH}_{\max } 24 \mathrm{~h}$ & 23.81 & 23.40 & 39.68 & 6 & 53.71 & 27.12 & 87.78 & 12 \\
\hline Diff MPH SDS & -2.13 & --3.73 & -0.85 & 13 & --1.67 & -2.81 & -0.34 & 19 \\
\hline IGF-I SDS & --1.02 & --2.56 & 1.34 & II & --0.98 & --4.62 & 1.08 & 17 \\
\hline *Leptin (ng/mL) & 3.96 & 2.14 & 5.93 & 12 & 2.40 & 1.21 & 4.30 & 17 \\
\hline \multicolumn{9}{|l|}{ During treatment } \\
\hline${ }^{*} \mathrm{GH}$ dose $(\mathrm{U} / \mathrm{kg} /$ day $)$ & 0.11 & 0.09 & 0.12 & 13 & 0.10 & 0.09 & 0.11 & 19 \\
\hline *Change in height SDS Ist yr & 0.96 & 0.89 & 1.26 & 13 & 0.42 & 0.25 & 0.51 & 19 \\
\hline
\end{tabular}

AITT, arginine - insulin tolerance test; $\mathrm{GH}_{\max }$, maximum peak of $\mathrm{GH}$ secretion; IGF-I, insulin-like growth factor I; AGA, appropriate for gestational age; SGA, small for gestational age; MPH midparental height; diffMPHSDS, difference in height SDS of the child versus its midparental height SDS $0.1 \mathrm{U} \mathrm{GH} / \mathrm{kg} /$ day $=33 \mu \mathrm{g} / \mathrm{kg} /$ day

The references used for SDS calculations are [8] for height and weigh and [9] for IGF-I.

$*$ indicates $\mathrm{p}<0.05$ between groups.

Serum fraction 6 run on CM10 arrays was identified as the most promising condition.

CM10 arrays were equilibrated twice with binding buffer (150 $\mu \mathrm{L} ; 100 \mathrm{mM}$ NaAcetate, $\mathrm{pH}$ 4.0). $10 \mu \mathrm{L}$ sample and $90 \mu \mathrm{L}$ binding buffer were applied on spots and mixed at room temperature using a DPC MicroMix 4 for $1 \mathrm{~h}$ for protein binding. Duplicate samples were analyzed for each patient at each time point. Arrays were washed three times in binding buffer, rinsed twice in $1 \mathrm{mM}$ HEPES, and air-dried. $0.6 \mu \mathrm{L}$ of a $50 \%$ solution of sinapinic acid (BioRad Laboratories) in $0.5 \%$ trifluoroacetic acid (Merck, Darmstadt, Germany) and 50\% acetonitril (Merck) was then applied twice to each spot as a matrix.

Time-of-flight spectra were generated using a PBS IIc ProteinChip reader (Bio-Rad Laboratories). Instrument settings for analysis were optimized in the mass range of 2.3$20.0 \mathrm{kDa}$ and data were averaged from 240 transients for each protocol. Samples were randomized and analyzed concurrently within 1 week by the same operator in order to minimize experimental variation. One reference serum sample was randomly applied on each array. The mass accuracy was calibrated in the molecular range of 5-18 $\mathrm{kDa}$ using external calibrators from Bio-Rad Laboratories. The same calibration equation was used for all samples.

\section{Data preprocessing}

Data handling was performed using ProteinChip Data Manager (Bio-Rad Laboratories). All spectra were baseline-subtracted and normalized according to total ion current, using an external normalization coefficient. Settings for peak identification and clustering of peaks across multiple spectra were first pass signal-to-noise ratio $(\mathrm{S} / \mathrm{N})>5$ in $15 \%$ of all spectra and second pass $\mathrm{S} / \mathrm{N}>3$, with a cluster mass window $0.3 \%$ of the mass.

Spectra were visually inspected and data for patients were excluded from further analysis if duplicated profiles differed or if the overall quality was low in one or both of the spectra (i.e. high noise, overall low peak intensity or a normalization factor exceeding 2 ). This process resulted in 33 valid peaks with mass/charge $(\mathrm{m} / \mathrm{z})$ values between 2.5 and $20.0 \mathrm{kDa}$. The average coefficient of variation (CV) for the 17 peaks detected in all of the reference samples was $18 \%(11-31 \%)$. 


\section{Statistics}

To identify peaks of potential interest, serum proteomic profiles for the high- and low-responder groups were compared before and after 1 year of treatment. Changes in maximum protein peak intensities during 1 year of $\mathrm{GH}$ treatment were also assessed.

Initially, ProteinChip Data Manager was used for calculation of p-values for single peaks. For paired statistics, ProteinChip Data Manager compared the mean values of peak clusters, by sample group, using the Wilcoxon signed-rank test.

\section{Multivariate statistics}

Subsequent multivariate data analysis was performed with Matlab software (version 7.3.0 R2006b, The Mathworks) on the mean intensity levels of the duplicate samples.

\section{Cross-validated stepwise regression}

Using stepwise regression, subsets of peaks were selected and assessed to examine the difference between high and low responders (before and 1 year after GH treatment) or the differences between pre-treatment and 1 year of $\mathrm{GH}$ treatment. Varying the input parameters of the stepwise regression generated a set of potential regression models. Only models where the final number of peaks selected was not more than $10 \%$ of the total number of samples were studied further. The best regression model was selected by tenfold cross-validation, where the tenfold cross-validation was repeated ten times in order to obtain more reliable estimates of the cross-validated $\mathrm{R}^{2}$.

\section{Relationships with other variables}

The procedures described above were also applied to explore the relationships between the peaks, instrumental and clinical variables, such as early growth data, parental height, IGF-I levels, leptin levels and the predicted response from published $\mathrm{GH}$ prediction models.

\section{Rotated two-component PLS regression/PLS discriminant analysis}

Partial least squares (PLS) regression was used to explore the relationships between the most predictive protein peaks. We selected between 2 and 15 of the peaks that had the highest correlation with the response variable and used the binary high/low-responder classification or the observed delta height SD scores after 1 year of GH treatment as the response variable. A two-component PLS regression was computed with two latent variables and then rotated in such a way that the first rotated component gave the ordinary least-squares regression on the response variable and the second rotated component had maximum residual variance for the predictor variables. If the response variable is a binary variable, the PLS regression is comparable to a PLS-discriminant analysis (PLS$\mathrm{DA})$, and in that case the first rotated component will give the discrimination function. The $\mathrm{R}^{2}$ and the tenfold crossvalidated $\mathrm{R}^{2}$ values of the PLS regression are presented. For the PLS-DA we also present the cross-validated correct rate of classification in percentage (CVcorrect).

\section{Analysis of systematic errors}

Principal component analysis (PCA), PLS regression and stepwise regression were used to analyze the impact of systematic errors on the results. For a few peaks there was a weak linear relationship between peak intensity and storage time. The influence of storage time on peak intensity was corrected for using linear regression. Two peaks $(\mathrm{m} / \mathrm{z}$ values of 4.149 and $4.182 \mathrm{kDa}$ ) had a non-linear relationship with storage time and were therefore excluded from further data analysis.

\section{Protein identification Immunodepletion}

Fractionated serum was immunodepleted using rabbit anti-transthyretin (DAKO, Glostrup, Denmark) or antiapolipoprotein A-II (GenScript Corporation, Piscataway, NJ) antibodies and dynabeads (Invitrogen, Carlbad, CA) coated with anti-rabbit IgG. Dynabeads were washed twice in $1 \mathrm{~mL}$ PBS (PAA Laboratories GmbH, Pasching, Austria) and resolved in $0.5 \mathrm{~mL}$ PBS. $4 \mu \mathrm{g}$ of antibody was added per $50 \mu \mathrm{L}$ dynabeads and incubated over night at $4^{\circ} \mathrm{C}$ on a rotation mixer (REAX 2 , Heidolph, Schwabach, Germany). Unbound antibodies were removed by washing twice in $1 \mathrm{~mL}$ PBS. The beads were resolved in $50 \mu \mathrm{L}$ PBS, and $20 \mu \mathrm{L}$ of fractionated serum was then added followed by incubation for $1 \mathrm{~h}$ at $4^{\circ} \mathrm{C}$ on a rotation mixer, followed by two washes in $1 \mathrm{~mL}$ PBS. The depleted serum was analyzed on CM10 arrays.

\section{In-gel protein digestion}

In-gel protein digestion with trypsin was, with some minor modifications, performed as described by Shevchenko et al. [10].

Nanoflow liquid chromatography/tandem MS (LC -MS/MS) Fourier transform ion cyclotron MS (FT/ICR MS)

Two-microliter sample injections were made with an HTC-PAL autosampler (CTC Analytics AG, Zwingen, Switzerland) connected to an Agilent 1100 binary pump (Agilent Technologies, Palo Alto, CA, USA). The peptides were trapped on a precolumn $(45 \times 0.075 \mathrm{~mm}$ i.d. $)$ packed with $3 \mu \mathrm{m} \mathrm{C}_{18}$-bonded particles and separated on a reversed phase column, $200 \times 0.050 \mathrm{~mm}$. Both columns are packed in-house with $3 \mu \mathrm{m}$ Reprosil-Pur $\mathrm{C}_{18}$-AQ particles. A 40 min gradient $10-50 \% \mathrm{CH} 3 \mathrm{CN}$ in $0.2 \% \mathrm{COOH}$ was used for separation of the peptides. 
Nanoflow LC-MS/MS was performed on a hybrid linear ion trap-FTICR mass spectrometer (LTQ-FT, Thermo Electron, Bremen, Germany). The spectrometer was operated in data-dependent mode, automatically switching to MS/ MS mode. MS-spectra were acquired in the FTICR, while MS/MS-spectra were acquired in the LTQ-trap. All the tandem mass spectra were searched by MASCOT (Matrix Science, London, UK) against the SwissProt 5.16 database. The search parameters were set to: MS accuracy $5 \mathrm{ppm}$, MS/MS accuracy $0.5 \mathrm{Da}$, one missed cleavage by trypsin allowed, fixed propionamide modification of cysteine and variable modification of oxidized methionine.

\section{Results}

Changes in protein expression profile in response to $\mathrm{GH}$ during the first year of treatment

In all data analyses, both the binary variable low versus high responder, and the continuous variable first year delta height $\mathrm{SD}$, were used as outcome variables. This produced similar results. For a number of the peaks identified, we found that the change in peak intensity during the first year of treatment correlated with GH responsiveness. Thus, these peaks could be used as biomarkers for classifying patients as good or poor responders to GH treatment. Using information from between 2 and 15 peaks resulted in an $\mathrm{R}^{2}$ in the range of $0.47-0.51$ and a CVcorrect in the range of $82-64 \%$ (Table 2, Figure 2). The 15 most predictive peaks identified by the rotated two-component PLS regression analysis are shown in Table 2. Using information on the intensity changes of the peaks with $\mathrm{m} / \mathrm{z}$ values of 13.877 and $17.139 \mathrm{kDa}, 82 \%$ of the study subjects could be correctly classified as low or high responders, respectively. Including more than two peaks in the analysis did not improve classification.

The middle panel in Figure 2A shows that auxological data correlated with changes in the maximum intensity of the $13.877 \mathrm{kDa}$ peak, and that variables associated with the GH/IGF-I axis, including IGF-I levels, leptin levels and $\mathrm{GH}_{\max } 24 \mathrm{~h}$, correlated with changes in the intensity of the $17.139 \mathrm{kDa}$ peak. Mean spectra of the 13.877 and 17.139 kDa peaks for high and low responders were created (Figure 3). As shown in the figure, in the high-responder group the intensities of both peaks decreased during the first year of GH treatment. In the low-responder group, the intensity of the $13.877 \mathrm{kDa}$ peak was increased during the first year of treatment, whereas the intensity of the $17.139 \mathrm{kDa}$ peak was unchanged during treatment.

\section{Protein profiles before start of $\mathrm{GH}$ treatment}

We were then interested to explore whether protein expression profiles could also be used to predict the

Table 2: The most predictive peaks identified by rotated two-component PLS regression analysis.

\begin{tabular}{|c|c|c|c|}
\hline Number of peaks & $\mathrm{R}^{2}$ & CVcorrect & First year growth hormone responsiveness Peak $\mathrm{m} / \mathrm{z}$ value $(\mathrm{kDa})$ \\
\hline 15 & 0.51 & 64 & $\begin{array}{l}\text { I7.584, } 17.383,17.256,17.139,13.788,9.127,8.820,8.689,6.833,6.626,6.474,6.428,4.401,3.212 \text { and } \\
3.311\end{array}$ \\
\hline 5 & 0.47 & 76 & $13.877,17.139,17.256,17.584$ and 6.428 \\
\hline 4 & 0.47 & 78 & $13.877,17.139,17.256$ and 17.584 \\
\hline 3 & 0.47 & 81 & $13.877,17.139$ and 17.256 \\
\hline \multirow[t]{2}{*}{2} & 0.47 & 82 & 13.877 and 17.139 \\
\hline & & & Before treatment \\
\hline 15 & 0.32 & 59 & $\begin{array}{l}3.311,4.401,4.463,7.010,8.689,8.820,9.709,13.877,14.040,14.142,15.132,17.139,17.256,17.584, \\
28.067\end{array}$ \\
\hline 5 & 0.23 & 63 & $14.040,14.142,17.139,17.256,28.067$ \\
\hline 4 & 0.24 & 65 & $14.142,17.139,17.256,28.067$ \\
\hline 3 & 0.32 & 74 & $9.361,14.040,17.256$ \\
\hline 2 & 0.17 & 59 & $17.139,17.256$ \\
\hline
\end{tabular}

The most predictive peaks identified by rotated two-component PLS regression analysis when $2,3,4,5$ and I5 peaks were included in the analysis. For each model the $\mathrm{R}^{2}$-value and correct rate of classification (CVcorrect) are presented. It is the peak intensity changes during the first year of $\mathrm{GH}$ treatment that are used in the analyses. 
A

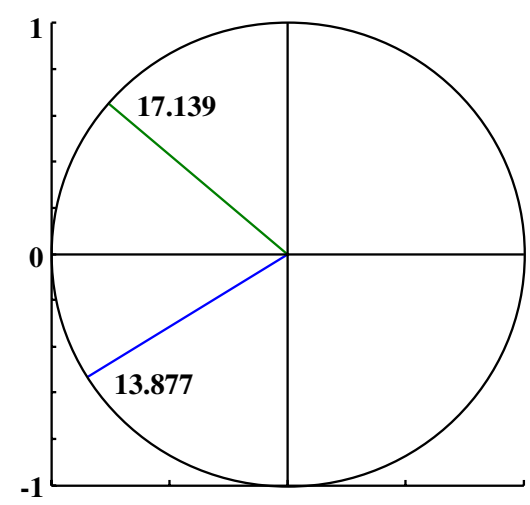

Background variables

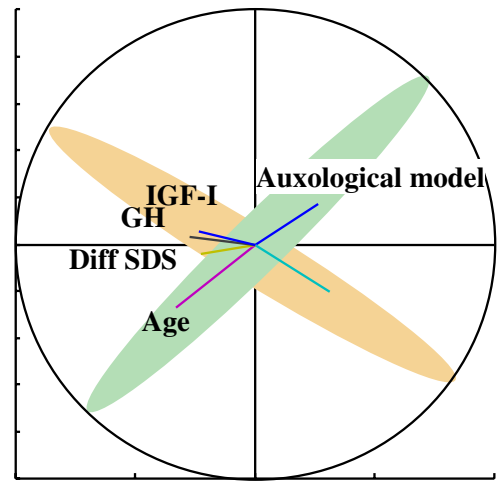

Low/high responders

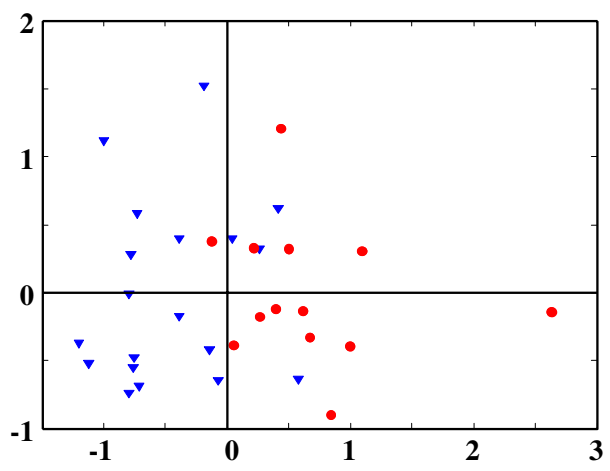

B

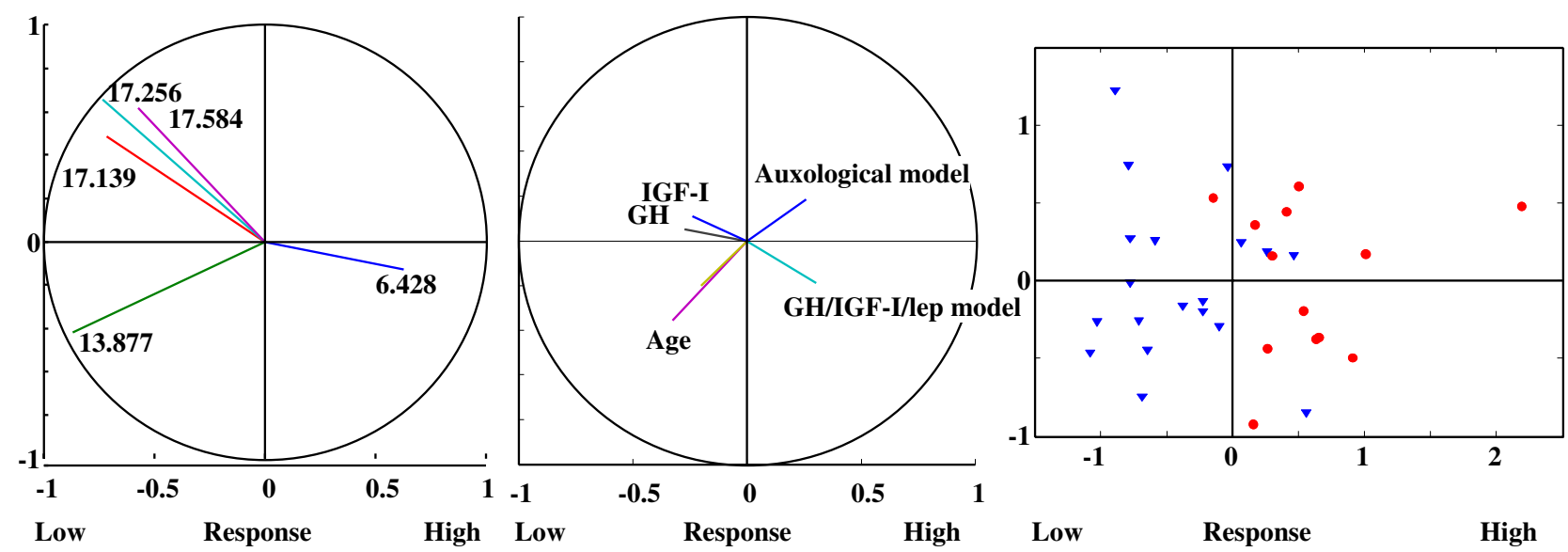

Figure 2

Computerized selection of the most predictive peaks for discrimination between high and low responders to GH treatment. The figure shows the rotated partial least squares regression using the 2 (A) and 5 (B) most predictive protein peaks. In all analyses, changes in the peak intensity during the first year of GH treatment are used. The left panels demonstrate which peaks are selected and the degree to which they correlate with the first dimension (low/high response on the $\mathrm{x}$ axis). The first dimension (Predicted response) is a weighted sum of the selected peaks and gives the best prediction of the binary low/high-response variable. A positive correlation with the first dimension indicates that the maximum peak intensity has increased more for the high responders than low responders during I year of treatment, whereas a negative correlation indicates that the maximum peak intensity has increased more for the low responders. The second dimension is a residual component. Residual, in the sense that it has no correlation with the response variable and, component, in the sense that it of all the selected predictor variables it explains the maximum variance. The use of this dimension facilitates the discovery of clusters of related peaks, or peaks conveying comparable information. In the middle panels, correlations of dimensions I and 2 with phenotype are shown. The right panels illustrate the discrimination of the individual low and high responders using the selected peaks. Low responders are shown as triangles; high responders as circles.

growth response and level of GH responsiveness before start of treatment. Using the same statistical methods as described above, we found that information from between 2 and 15 peaks resulted in an $\mathrm{R}^{2}$ in the range of $0.17-0.32$ and a CVcorrect in the range of 74-59 \% (Table 2 ). The best model for prediction of GH response before start of treatment was obtained when the 3 peaks with $\mathrm{m} /$
$\mathrm{Z}$ values of $9.361,14.040$ and $17.256 \mathrm{kDa}$ were included in the model $\left(\mathrm{R}^{2}=0.32\right.$, CVcorrect $\left.=0.74\right)$.

\section{Identification of selected peaks}

After identifying specific peaks that could be used to discriminate between high and low responders to GH treatment, we wanted to identify the proteins representing the 

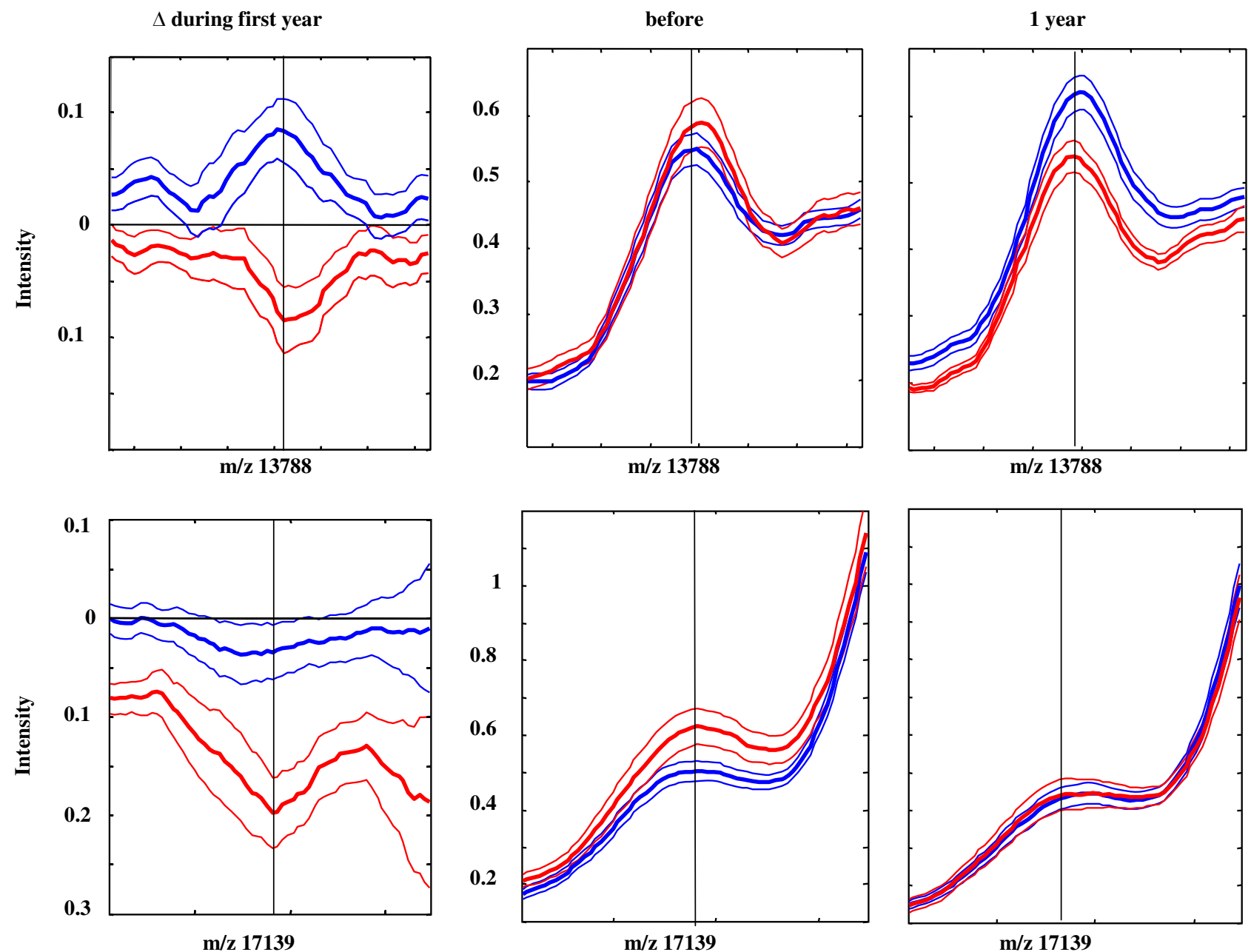

\section{Figure 3}

Change in mean peak intensities. Change in mean peak intensity (thick line) \pm SEM during the first year of GH treatment (left panels), before the start (middle panels) after I year of treatment (right panels) for the I3.788 and the I7.I39 kDa peaks that were most predictive for discrimination between children with a high (red) or low (blue) growth response to treatment.

most predictive peaks. From the consistency of the peak pattern in the spectra, the peaks with $\mathrm{m} / \mathrm{z}$ values around $14 \mathrm{kDa}$ were recognized as different posttranslational modified forms of transthyretin; the $13.877 \mathrm{kDa}$ peak was recognized as the unmodified form and the $14.040 \mathrm{kDa}$ peak was recognized as the cysteinylated form. The 17.139 and 17.256 kDa peaks were recognized as dimers of apolipoprotein A-II (Apo A-II), the 8.609 and $4.401 \mathrm{kDa}$ peaks were recognized as truncated forms of Apo A-II, and the 6.428 and $3.212 \mathrm{kDa}$ peaks were recognized as truncated forms of Apo C-I. To verify the identities of the two most discriminating proteins we performed serum depletion experiments using specific antibodies and MS protein identification.

An anti-human transthyretin antibody depleted both a $12.865 \mathrm{kDa}$ peak, formerly identified as a fragment of transthyretin [11], and a group of peaks around $14 \mathrm{kDa}$, including the 13.877 and 14.040 serum peaks (Figure 4). Using the anti-Apo A-II antibody, we were not able to deplete any peaks. However, when the quality of the antibody was checked by SELDI-TOF we found very low amounts of full-length antibodies and high levels of light and heavy chains. Therefore, serum fraction 6 was separated on a 1D SDS PAGE and bands in the area around 17 $\mathrm{kDa}$ where cut out, trypsin digested and the resultant samples underwent MS identification. The result indicated that the samples were not pure. After common impurities like keratin had been excluded, there were eight potential proteins left for evaluation. The proteins were in the following order based on the number of assigned peptides: Apo A-II, serum amyloid A 4, hemoglobin subunit alpha, Apo A-I, hemoglobin subunit beta, transthyretin, histone H4 and albumin. Apo A-II had the highest number of 


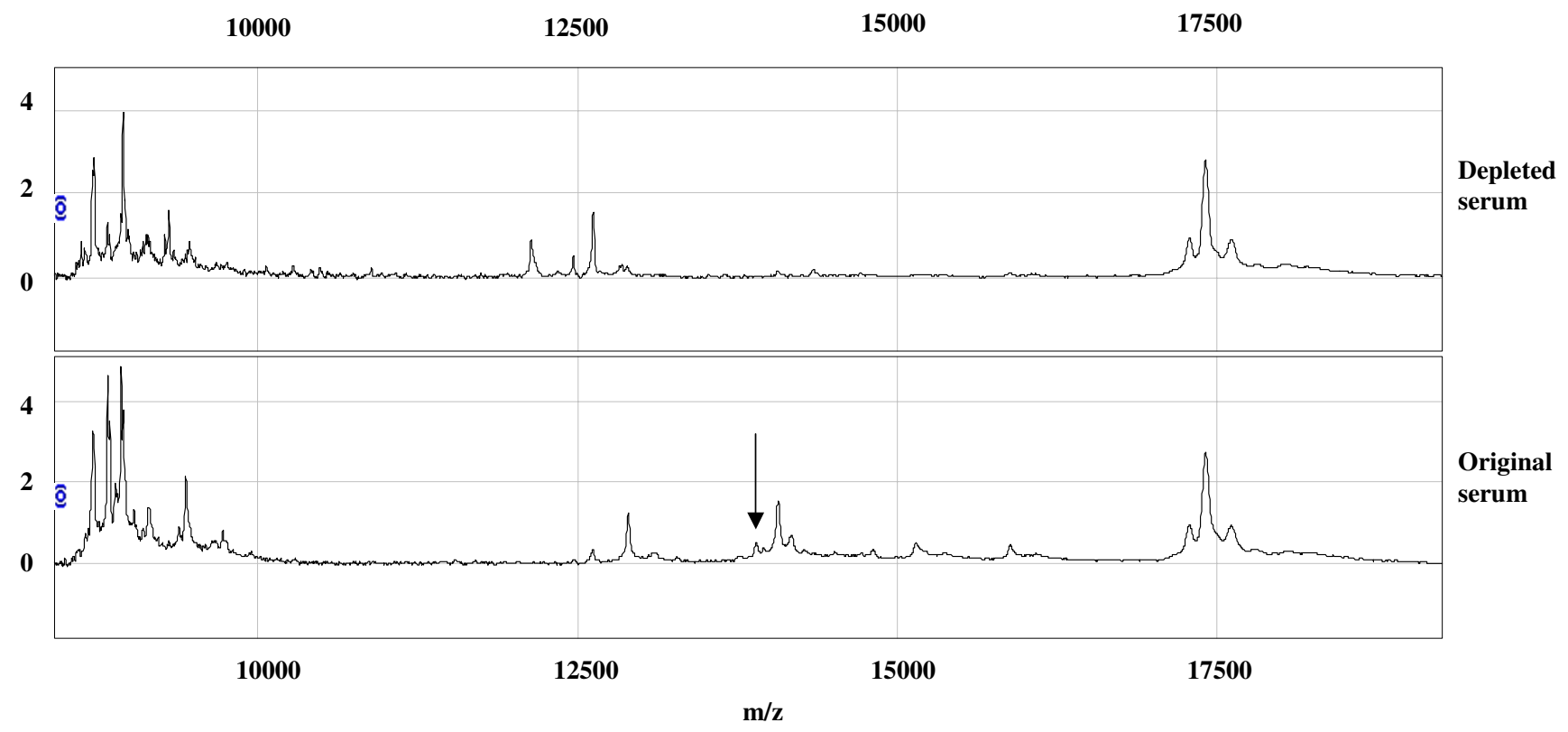

\section{Figure 4}

Depletion of transthyretin from serum using specific anti-transthyretin antibodies. The upper panel represents the depleted serum and the lower panel represents the original sera before depletion. The peak with the molecular mass of I 3.877 $\mathrm{kDa}$ is indicated by an arrow.

assigned peptides. The MS identification results, together with the characteristic serum profile pattern, strongly suggest that the 17.139 and $17.256 \mathrm{kDa}$ peaks represent Apo A-II.

\section{Discussion}

The present study utilized a pharmaco-proteomic approach in order to identify novel biomarkers that can be used to predict growth in response to GH treatment in short prepubertal children with idiopathic short stature. Using this approach we identified two peaks that together enabled the correct classification of $82 \%$ of the study subjects as either good or poor responders to GH treatment. Through further analysis, using a combination of the specific peak patterns within the spectra, results from serumdepletion experiments and MS identification, we identified these peaks to represent transthyretin and Apo A-II.

One of the two most discriminatory peaks in the present study was the unmodified form of transthyretin, also known as prealbumin. In addition to its functions as a carrier of serum thyroxine and triiodothyronine and a transporter of retinol [12], transthyretin is known as a marker of nutrition. Studies have shown that in cases of malnutrition there is a poor growth response to GH [13]. Clinical studies also show that a high leptin level, a marker of adipocyte tissue mass, at start of GH treatment correlates with a better growth response [14]. The intensity of the transthyretin peak increased in the low-responder group and decreased in the high-responder group during GH treatment. Interestingly, GH administration has also been shown to increase serum levels of transthyretin in severely burned children and in adults after hepatectomy $[15,16]$, suggesting a common mechanism between serious illness and low GH responsiveness. Our results are in line with a report showing that serum levels of transthyretin in rats were markedly decreased by hypophysectomy and further decreased after GH replacement [17]. Furthermore, transthyretin has been shown to play a role in type 1 diabetes. Patients with type 1 diabetes had lower serum levels of transthyretin than healthy controls. In addition, the transthyretin tetramer, in contrast to the transthyretin monomer, promoted insulin release [18].

The second most predictive peak was Apo A-II. This peak remained unchanged in the low responders, but decreased in the high responders after GH treatment. Apo A-II is the second most abundant protein component of high-density lipoprotein (HDL)-cholesterol but little is known about its role in HDL metabolism. GH plays a role in lipid and lipoprotein metabolism in man, increasing both the uptake and degradation of low-density lipoproteins [19]. A study of GH-deficient children suggested that GH had no effect on serum Apo A-II levels [20]. Experiments using 
mouse models have shown a role for Apo A-II in glucose homeostasis: Apo A-II-deficient mice showed improved insulin sensitivity, whereas transgenic mice over-expressing murine Apo A-II showed insulin resistance and obesity [21]. Apo A-II has also been suggested as a candidate gene in type 2 diabetes [22-24].

Using rotated two-component PLS regression and PLS discriminant analysis, we have shown that the protein peak corresponding to transthyretin correlates with auxological data as shown in Figure 2. Moreover, apolipoprotein levels appear to correlate with changes in the GH/IGF/leptin axis. This could partly explain the influence of nutrition on GH responsiveness. However, our results must be validated on an independent patient sample.

In this study we analyzed serum protein profiles from before the start of GH treatment and after 1 year of treatment. This time period was selected as growth response during 1 year has been shown to give an estimate of GH responsiveness, known as the response score. We were interested to see whether changes during this time period in the expression of the novel biomarkers identified could be of additional value in predicting long term prepubertal growth $[25,26]$.

In order to predict the growth response to GH treatment, it is preferable to be able to use pre-treatment data. From the protein profiles before the start of treatment we were able to create a model based on the intensity levels of three peaks. However, this model was not as robust as the model for changes in response to GH treatment. The optimal time period needed to ascertain changes that may be of utility in predicting final height is certain different for different variables. For example, we know that short-term changes in serum IGF-I levels are a better predictor of growth response than serum levels of IGF-I before the start of treatment [27]. In this context, it would also be of interest to analyze short-term changes in protein profiles after the start of treatment, for example after 1-2 weeks.

SELDI-TOF is a complementary technology to other proteomic techniques like 2D gel electrophoresis; for our purposes, a major advantage is that SELDI-TOF is a high throughput technique and is therefore more suitable for analyzing a large quantity of samples than 2D gel electrophoresis. Furthermore, SELDI-TOF technology has an improved sensitivity in the mass range $<25 \mathrm{kDa}$, whereas 2D electrophoresis has a high resolution and sensitivity between 20 and $150 \mathrm{kDa}$. The reproducibility and reliability of the SELDI-TOF-MS proteomic system have been discussed [28-30]. Transit time, storage conditions, clotting time and tube type used can affect protein profiles [31,32], which has raised concerns about using samples from retrospective studies. However, proper handling of samples can minimize these shortcomings [33], and in the present study we took special precautions to ascertain standardization. Samples were stored at $-70^{\circ} \mathrm{C}$ and were not thawed until used for analysis. They were randomized to each bioprocessor and the analyses were run within a week by the same operator. A reference sample was applied on each array. Using PCA, PLS regression and stepwise regression, we did not detect systematic errors correlated with non-GH-dependent factors or instrumental biases such as array or spot number, but for some peaks we found a weak linear relationship between peak intensity and storage time, which was adjusted for in all data analyses. Two peaks with a non-linear relationship to storage time were excluded from further analysis. The average CV of $18 \%$ for 17 peaks in the reference samples was in the expected range for this method [34].

In order to find peaks related to $\mathrm{GH}$ responsiveness we used an integrated strategy, combining the results from cross-validated stepwise regressions and PLS regressions. The best distinction between good and poor responders over the first year of GH treatment was obtained using two peaks; adding more peaks into the model increased background noise.

Reciprocal relationships between the most predictive peaks were visualized with rotated PLS regression to explore the formation of clusters of peaks containing comparable information. As the target response variable, we explored the prediction of the binary low/high response and the first year growth response in height SD score; results were similar.

Only one previous study has utilized SELDI-TOF proteomics to search for GH-dependent biomarkers [35]. In this study the aim was to identify novel biomarkers of GH administration in adult athletes. A peak of $15.1 \mathrm{kDa}$ was identified as the most effective classifier of subjects receiving GH. This peak was identified as hemoglobin $\alpha$-chain (HbA1). We did not identify this peak to be influenced by GH treatment in short children, possibly due to the different study groups and different ProteinChip surfaces that were utilized in the two studies.

From the information of isoelectric points, the known GH-dependent proteins IGF-I, IGFBP-3, leptin and insulin are not expected to be identified in protein profiles from serum fraction 6 on CM10 arrays. IGF-I is expected to be detected in fraction 1, and IGFBP-3, leptin and insulin are expected to be detected in fraction 3. In the pilot study of four good and four poor responders, performed with all fractions on three array surfaces, a $7.643 \mathrm{kDa}$ peak corresponding to the mass of IGF-I, was detected on CM10 arrays in fraction 1 . This peak was up-regulated by $70 \%$ during the first year of GH treatment in the high- 
responder group, whereas there was no significant change in peak intensity in the low-responder group.

In summary, we have shown that analysis of serum protein expression patterns can be a useful method for identifying novel markers of GH responsiveness. In future, knowledge obtained using broad exploratory techniques, could possibly be used in the development of new clinical tools for diagnosis and treatment.

\section{Conclusion}

In this study we show that a pharmaco-proteomic approach can be used in order to identify novel biomarkers that can be used to discriminate between good and poor responders to GH treatment among short prepubertal children with ISS. Optimal results were obtained when changes in peak intensity during first year of treatment were analyzed. Using this approach we identified two peaks that together enabled the correct classification of $82 \%$ of the study subjects as either good or poor responders to GH treatment. Through further analysis, using a combination of the specific peak patterns within the spectra, results from serum-depletion experiments and MS identification, these peaks were identified to represent transthyretin and Apo A-II. These results suggest that these proteins may have a role in determining GH sensitivity.

\section{Abbreviations}

GH: growth hormone; GHD: growth hormone-deficient; ISS: idiopathic short stature; SDS: standard deviation score; SELDI-TOF-MS: surface-enhanced desorption/ionization time-of-flight mass spectrometry; Apo A-II: apolipoprotein A-II; IGF-I: insulin-like growth factor I; $\mathrm{GH}_{\max }$ : maximum peak of GH secretion; AITT: arginine-insulin tolerance test; IGFBP-3: IGF-binding protein 3; S/N: signal-to-noise ratio; $\mathrm{m} / \mathrm{z}$ : mass/charge; $\mathrm{CV}$ : coefficient of variation; PCA: principal component analysis; PLS: partial least squares; PLS-DA: PLS-discriminant analysis; CVcorrect: correct rate of classification in percentage; MS LC MS/MS: liquid chromatography/tandem MS; FT/ICR MS: Fourier transform ion cyclotron MS; HDL: high-density lipoprotein; HbA1: hemoglobin $\alpha$-chain.

\section{Competing interests}

KAW declares that she has an unrestricted research grant from Pharmacia/Pfizer. AFMN works for Muvara, Multivariate Analysis of Industrial and Research Data Statistical Consultation, The Netherlands. GH, BA, JD, and ZH declare that they have no competing interests.

\section{Authors' contributions}

GH, BA, AFMN, JD, ZH and KAW have all given substantial contribution to conception and design, analysis and interpretation of the data. GH and BA have designed and carried out all the SELDI-TOF and additional experiments.
AFMN performed all of the statistical analyses. GH, BA, AFMN, JD, ZH and KAW have all been involved in drafting the manuscript and have revised it critically for important intellectual content.

\section{Acknowledgements}

The authors are thankful for fruitful discussions with Peter Iversen and Eva Fernvik at Bio-Rad, and the core facility at Sahlgrenska Academy at University of Gothenburg for their work with mass spectrometry protein identification. The study was supported by a grant from the Lundberg Research foundation for the SELDI-TOF as well as grants from the Research Foundation (7509) the Göteborg University/Sahlgrenska University Hospital (ALF) and Åke Wiberg Foundation, Wilhelm \& Martina Lundgrens Vetenskapsfond and Frimurarna Barnhusdirektionen Foundation.

\section{References}

I. Rosenfeld RG: Pharmacogenomics and pharmacoproteomics in the evaluation and management of short stature. European journal of endocrinology/European Federation of Endocrine Societies 2007, I57(SuppI I):S27-3I.

2. Rosenfeld RG: The molecular basis of idiopathic short stature. Growth Horm IGF Res 2005, I 5(Suppl A):S3-5.

3. Hochberg Z, Albertsson-Wikland K: Evo-devo of infantile and childhood growth. Pediatr Res 2008, 64(I):2-7.

4. Kristrom B, Lofqvist C, Rosberg S, Albertsson Wikland K: Effect of spontaneous $\mathrm{GH}$ secretion and the $\mathrm{GH}$ sampling period on the accuracy of models for predicting growth responses to GH treatment. J Clin Endocrinol Metab 200I, 86( I 0):4963-4964.

5. Ranke MB, Lindberg A, Chatelain P, Wilton P, Cutfield W, Albertsson-Wikland $K$, Price DA: Derivation and validation of a mathematical model for predicting the response to exogenous recombinant human growth hormone (GH) in prepubertal children with idiopathic GH deficiency. KIGS International Board. Kabi Pharmacia International Growth Study. J Clin Endocrinol Metab 1999, 84(4): I I 74- I I83.

6. Wikland KA, Kristrom B, Rosberg S, Svensson B, Nierop AF: Validated multivariate models predicting the growth response to $\mathrm{GH}$ treatment in individual short children with a broad range in GH secretion capacities. Pediatr Res 2000 , 48(4):475-484.

7. Dahlgren J, Kristrom B, Niklasson A, Nierop AF, Rosberg S, Albertsson-Wikland $\mathrm{K}$ : Models predicting the growth response to growth hormone treatment in short children independent of GH status, birth size and gestational age. BMC Med Inform Decis Mak 2007, 7(I):40.

8. Albertsson-Wikland K, Luo ZC, Niklasson A, Karlberg J: Swedish population-based longitudinal reference values from birth to 18 years of age for height, weight and head circumference. Acta Paediatr 2002, 9 I(7):739-754.

9. Löfqvist C, Andersson E, Gelander L, Rosberg S, Blum WF, Albertsson-Wikland K: Reference values for IGF-I throughout childhood and adolescence: a model that accounts simultaneously for the effect of gender, age, and puberty. J Clin Endocrinol Metab 200I, 86( I 2):5870-5876.

10. Shevchenko A, Tomas H, Havlis J, Olsen JV, Mann M: In-gel digestion for mass spectrometric characterization of proteins and proteomes. Nature protocols 2006, I(6):2856-2860.

II. Kozak KR, Su F, Whitelegge JP, Faull K, Reddy S, Farias-Eisner R: Characterization of serum biomarkers for detection of early stage ovarian cancer. Proteomics 2005, 5( I 7):4589-4596.

12. Escher N, Kaatz M, Melle C, Hipler C, Ziemer M, Driesch D, Wollina $U$, von Eggeling F: Posttranslational modifications of transthyretin are serum markers in patients with mycosis fungoides. Neoplasia 2007, 9(3):254-259.

13. Thissen JP, Underwood LE, Ketelslegers JM: Regulation of insulinlike growth factor-I in starvation and injury. Nutrition reviews 1999, 57(6): $167-176$.

14. Kristrom B, Carlsson B, Rosberg S, Carlsson LM, Albertsson-Wikland $\mathrm{K}$ : Short-term changes in serum leptin levels provide a strong metabolic marker for the growth response to growth hormone treatment in children. Swedish Study Group for 
Growth Hormone Treatment. I Clin Endocrinol Metab 1998, 83(8):2735-274I.

15. Connolly CM, Barrow RE, Chinkes DL, Martinez JA, Herndon DN: Recombinant human growth hormone increases thyroid hormone-binding sites in recovering severely burned children. Shock (Augusta, Ga) 2003, 19(5):399-403.

16. Luo SM, Liang LJ, Lai JM: Effects of recombinant human growth hormone on remnant liver after hepatectomy in hepatocellular carcinoma with cirrhosis. World J Gastroenterol 2004 I0(9): 1292-I 296

17. Vranckx R, Rouaze-Romet M, Savu L, Mechighel P, Maya M, Nunez $E A$ : Regulation of rat thyroxine-binding globulin and transthyretin: studies in thyroidectomized and hypophysectomized rats given tri-iodothyronine or/and growth hormone. The Journal of endocrinology 1994, I42(I):77-84.

18. Refai E, Dekki N, Yang SN, Imreh G, Cabrera O, Yu L, Yang G, Norgren S, Rossner SM, Inverardi L, et al:: Transthyretin constitutes a functional component in pancreatic beta-cell stimulussecretion coupling. Proc Natl Acad Sci USA 2005, I 02(47): I 7020- I7025.

19. Hochberg Z, Hertz P, Maor G, Oiknine J, Aviram M: Growth hormone and insulin-like growth factor-I increase macrophage uptake and degradation of low density lipoprotein. Endocrinology 1992, I 3 I (I):430-435.

20. Kuromaru R, Kohno H, Ueyama N, Hassan HM, Honda S, Hara T: Long-term prospective study of body composition and lipid profiles during and after growth hormone (GH) treatment in children with GH deficiency: gender-specific metabolic effects. J Clin Endocrinol Metab 1998, 83( I I):3890-3896.

21. Castellani LW, Goto AM, Lusis AJ: Studies with apolipoprotein A-II transgenic mice indicate a role for HDLs in adiposity and insulin resistance. Diabetes 200I, 50(3):643-65I.

22. Elbein SC, Hoffman MD, Teng K, Leppert MF, Hasstedt SJ: A genome-wide search for type 2 diabetes susceptibility genes in Utah Caucasians. Diabetes 1999, 48(5): I I75-I 182

23. Hanson RL, Ehm MG, Pettitt DJ, Prochazka M, Thompson DB, Timberlake D, Foroud T, Kobes S, Baier L, Burns DK, et al:: An autosomal genomic scan for loci linked to type II diabetes mellitus and body-mass index in Pima Indians. American journal of human genetics 1998, 63(4): I |30-1 I38.

24. Vionnet N, Hani EH, Dupont S, Gallina S, Francke S, Dotte S, De Matos F, Durand E, Lepretre F, Lecoeur C, et al:: Genomewide search for type 2 diabetes-susceptibility genes in French whites: evidence for a novel susceptibility locus for earlyonset diabetes on chromosome 3q27-qter and independent replication of a type 2-diabetes locus on chromosome Iq2 Iq24. American journal of human genetics 2000, 67(6): $1470-1480$.

25. de Ridder MA, Stijnen T, Hokken-Koelega AC: Prediction of adult height in growth-hormone-treated children with growth hormone deficiency. I Clin Endocrinol Metab 2007, 92(3):925-931.

26. Reiter EO, Price DA, Wilton P, Albertsson-Wikland K, Ranke MB Effect of growth hormone (GH) treatment on the near-final height of I 258 patients with idiopathic GH deficiency: analysis of a large international database. J Clin Endocrinol Metab 2006, 9 I(6):2047-2054.

27. Albertsson-Wikland K, Hall K. Growth hormone treatment in short children: relationship between growth and serum insulin-like growth factor I and II levels. J Clin Endocrinol Metab 1987 65(4):67| -678.

28. Baggerly KA, Morris JS, Edmonson SR, Coombes KR: Signal in noise: evaluating reported reproducibility of serum proteomic tests for ovarian cancer. Journal of the National Cancer Institute 2005, 97(4):307-309.

29. Diamandis EP: Mass spectrometry as a diagnostic and a cance biomarker discovery tool: opportunities and potential limitations. Mol Cell Proteomics 2004, 3(4):367-378.

30. Diamandis EP. Serum proteomic profiling by matrix-assisted laser desorption-ionization time-of-flight mass spectrometry for cancer diagnosis: next steps. Cancer Res 2006, 66(II):5540-554I.

3I. Coombes KR, Morris JS, Hu J, Edmonson SR, Baggerly KA: Serum proteomics profiling - a young technology begins to mature. Nature biotechnology 2005, 23(3):291-292.

32. Karsan A, Eigl BJ, Flibotte S, Gelmon $K$, Switzer P, Hassell P, Harrison D, Law J, Hayes M, Stillwell M, et al.: Analytical and preanalytical biases in serum proteomic pattern analysis for breast cancer diagnosis. Clinical chemistry 2005, 5 I (8): I525-1528.

33. Timms JF, Arslan-Low E, Gentry-Maharaj A, Luo Z, T'Jampens D, Podust VN, Ford J, Fung ET, Gammerman A, Jacobs I, et al.: Preanalytic influence of sample handling on SELDI-TOF serum protein profiles. Clinical chemistry 2007, 53(4):645-656.

34. Rollin D, Whistler T, Vernon SD: Laboratory methods to improve SELDI peak detection and quantitation. Proteome science 2007, 5:9.

35. Chung L, Clifford D, Buckley M, Baxter RC: Novel biomarkers of human growth hormone action from serum proteomic profiling using protein chip mass spectrometry. I Clin Endocrinol Metab 2006, 9 I(2):67I-677.
Publish with Biomed Central and every scientist can read your work free of charge

"BioMed Central will be the most significant development for disseminating the results of biomedical research in our lifetime. "

Sir Paul Nurse, Cancer Research UK

Your research papers will be:

- available free of charge to the entire biomedical community

- peer reviewed and published immediately upon acceptance

- cited in PubMed and archived on PubMed Central

- yours - you keep the copyright 